\title{
Study of adiabatic localized shear in metals by split Hopkinson pressure bar method
}

\author{
V. Pushkova , A. Yurlov, A. Bol'shakov, A. Podurets, A. Kal'manov, and E. Koshatova \\ Russian Federal Nuclear Center - VNIIEF, 607190 Sarov, Russia
}

\begin{abstract}
This paper is devoted to the technique for study of localized shear using hatshaped samples by the split Hopkinson pressure bar (SHPB) method. Also it is devoted to results obtained in tests with samples of copper M1 and steel 09G2S. The tests were performed using hat-shaped samples with beforehand-determined direction of forced shear. Sizes of samples were thoroughly selected in order to minimize plastic deformation of the hat-shaped part and the ring base, which are in contact with the bar ends. Results of testing of copper M1 and steel 09G2S were obtained; "shear stress-displacement" diagrams were plotted. Values of amplitudes and durations of loading pulses were determined. Also shear stresses were determined when adiabatic localized shear was formed in case of this geometry of samples.
\end{abstract}

\section{Introduction}

Localization of adiabatic shear for plastic metals is one of destruction regimes. It has been studied for more than 50 years [1]. Urgency of this study is caused by the fact that the available theoretical approaches give unsatisfactory description of this type of deformation. The basic mechanism of this process is a fast local cycle consisting of plastic deformation of material, transition of work to heat, and thermal softening of material [2]. Studies of localized shear in copper, steels, titanium alloys, etc. were performed by various researchers with varying velocity and duration of loading. In some works, study of the complex process of shear localization was accompanied with numerical evaluation of temperature in shear band [3,4]. For example, for annealed and prestrained steel 304, the calculated temperature was 1500-3100 K in shear band [3]. It is higher than the melting temperature. At the same time, transmission electron microscopy revealed no any traces of melting. To describe formation and growth of adiabatic shear bands, models are under development, for example, the three-dimensional micromechanical model in [5].

In general, researchers admit that, though a large scope of data is obtained, growth of localized shear in materials has been insufficiently studied. These studies are required for investigation of localized shear as one of the types of heterogeneous deformation of materials, and for association of it with the parameters of loading and microstructure with the purpose to develop more physically-justified models of dynamic deformation and destruction of metals.

This paper is devoted to the method for study of localized shear using hat-shaped samples [6] by the split Hopkinson pressure bar (SHPB) method [3,7]. Also it is devoted to results obtained in tests with samples of copper M1 and steel 09G2S.

\footnotetext{
a e-mail: root.gdd@vniief.ru
}

This is an Open Access article distributed under the terms of the Creative Commons Attribution-Noncommercial License 3.0, which permits unrestricted use, distribution, and reproduction in any noncommercial medium, provided the original work is properly cited. 


\section{Method of study}

In the process of the method development, it was planned to perform tests using hat-shaped samples with beforehand specified direction of forced shear (see Fig. 1). Sizes of the samples were selected in order to minimize plastic deformation of the hat-shaped part and the ring basis of the sample [3]. The advantage of this sample geometry is that it facilitates formation of shear bands because of partial restraining of cavity formations due to compression stress during shear. On the other hand, the disadvantage of this construction is impossibility of precise measurement of shear deformation and the effect of expansion of the cylindrical basis during shear formation [3]. When shear flowability occurs in the shear section, normal stress in the hat-shaped part and the ring basis of the sample should be much lower than the yield strength of the sample material.

Figure 1 presents the experimental setup of these studies by the SHPB method, when samples with dimensions of $\varnothing 10 \times 5 \mathrm{~mm}$ were placed between ends of the measuring bars.
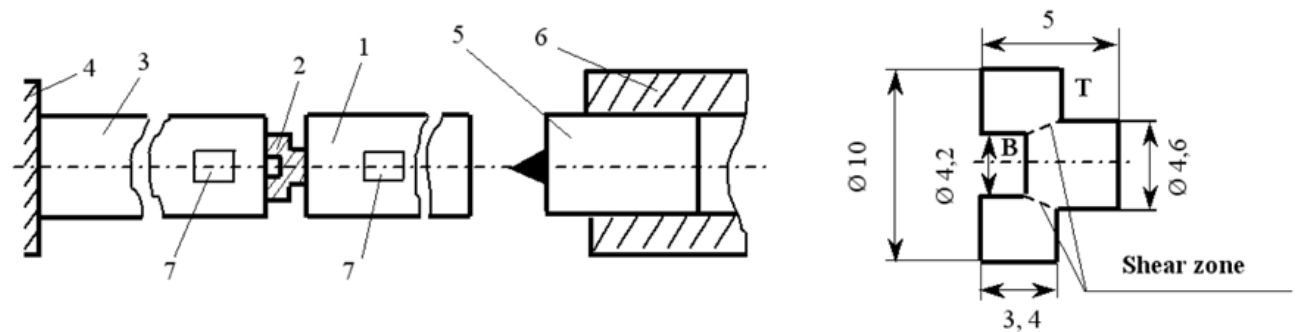

Fig. 1. Experimental setup and sizes of sample for tests aimed to study localized shear by SHPB method: 1 - loading bar; 2 - sample; 3 - support bar; 4 - stop block; 5 - impactor; 6 - air gun; 7 - strain gauge.

Pulse loading in the loading bar was provided by impactors made of KhVG steel (diameter of $20 \mathrm{~mm}$, length of $300-420 \mathrm{~mm}$ ), which were accelerated by the air gun up to the velocities from 4.5 to $8 \mathrm{~m} / \mathrm{s}$. In the tests, impactor velocity and strains in the loading bar and the support bars were recorded. Basing on strain pulses, displacement of the sample ends regarding to each other and the shear stress in the sample were determined.

\section{Results of study}

The copper samples were loaded by impactors having lengths of 420 and $300 \mathrm{~mm}$, which were accelerated with velocities of 4.5 and $5.3 \mathrm{~m} / \mathrm{s}$. In these tests, durations of the loading pulses were $t_{1}=168$ and $t_{2}=120 \mu \mathrm{s}$, and amplitudes of the loading pulses were $A_{1}=A_{2}=400 \mathrm{MPa}$. Displacements of the samples, which were measured after conduction of the tests, were 1.7 and $2.6 \mathrm{~mm}$, respectively. Figure 2 presents the dependences of shear stress on displacement in the tests with copper M1.

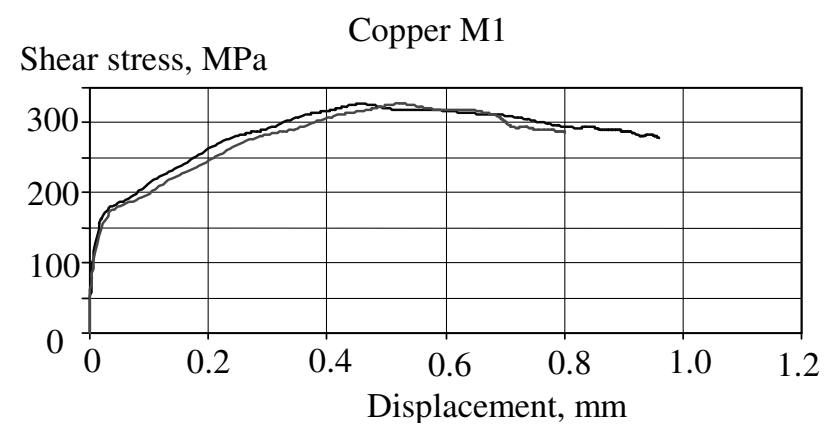

Fig. 2. Shear stress versus displacement for copper M1. 
Figure 2 shows that the dependences "shear stress - displacement" have a characteristic view with a clearly pronounced point of the maximum shear stress $\sigma_{S}=325 \mathrm{MPa}$, after which the drop is observed. This response reflects the state of saturation of the ability for strain hardening, and it identifies the point, which is the beginning of prevalence of the softening processes during further deformation of the sample. From the point of view of the criterion of the maximum stress for instability occurrence, which is of common use for analysis of adiabatic shear, the maximum shear stress is usually considered as a point of instability beginning, after which the material deformation starts localizing as a shear band. Also formation of shear bands in these tests is confirmed when studying microstructures of the tested samples.

Figure 3 presents microstructure of shear zones in the tests with copper. Localized shear band is observed in these zones.

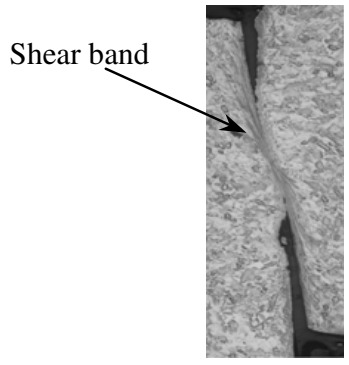

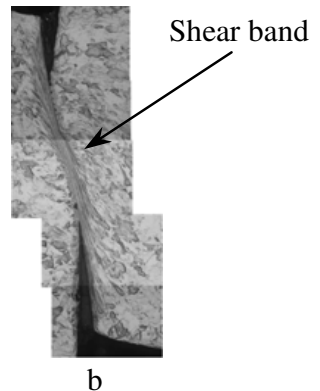

b

Fig. 3. Microstructure of shear zone in copper M1: a) $t=168 \mu \mathrm{s}, A=400 \mathrm{MPa}$, final displacement is $\Delta=1.7 \mathrm{~mm}$; b) $t=120 \mu \mathrm{s}, A=400 \mathrm{MPa}$, final displacement is $\Delta=1.6 \mathrm{~mm}$.

The samples of steel 09G2S were loaded by impactor having length of $420 \mathrm{~mm}$, which was accelerated with velocities of 4.5 and $7.7 \mathrm{~m} / \mathrm{s}$. In the tests with steel, durations of the loading pulses were $t_{1}=t_{2}=168 \mu \mathrm{s}$. The amplitudes of the loading pulses were $A_{1}=877, A_{2}=850 \mathrm{MPa}$. Values of displacements of the samples, which were measured after the tests, were $\Delta=0.7$ and $1.6 \mathrm{~mm}$, respectively.

Figure 4 presents the obtained dependences of shear stress on displacement in the tests with steel 09G2S.

The dependences for steel 09G2S, as well as for copper, have a characteristic view with a clearly pronounced point of the maximum shear stress, which is $\sigma_{S} \sim 700 \mathrm{MPa}$ for steel, after which the curve starts dropping. As it was mentioned above, this type of curves is typical during formation of localized shear bands. To confirm this fact, microstructures of steel samples were studied. Figure 5 presents microstructure of the shear zone in the tested steel 09G2S.

Analysis of structures of the samples made of steel 09G2S (Fig. 5) and comparison of the curves in Fig. 4 reveal that a developed shear band is observed when shear stress is $\sigma_{S}=700 \mathrm{MPa}$ and pulse duration is $t=168 \mu \mathrm{s}$. While a strong shear strain is observed in all operational section of the sample, forestalling the beginning of localization at stress $\sigma_{S}=678 \mathrm{MPa}$.

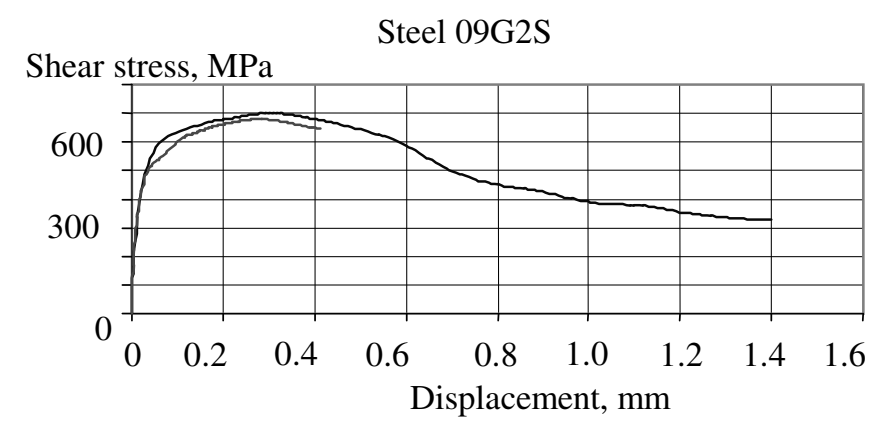

Fig. 4. Change of shear stress depending on displacement for steel 09G2S. 


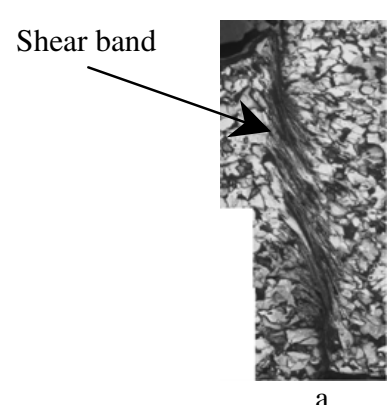

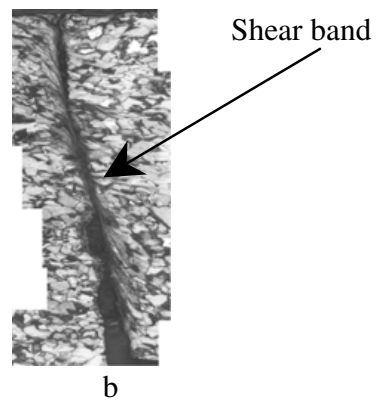

Fig. 5. Microstructure of shear zone in steel 09G2S: a) $t=168 \mu \mathrm{s}, A=850 \mathrm{MPa}, \sigma_{S}=678 \mathrm{MPa}$, final displacement is $\Delta=0.7 \mathrm{~mm}$; b) $t=168 \mu \mathrm{s}, A=877 \mathrm{MPa}, \sigma_{S}=700 \mathrm{MPa}$, final displacement is $\Delta=1.6 \mathrm{~mm}$.

\section{Conclusion}

Results of testing of copper M1 and steel 09G2S were obtained, diagrams "shear stress - displacement" were plotted, and the results were analyzed. During the study, the authors determined values of amplitudes and durations of loading pulses, as well as shear stresses when adiabatic localized shear occurred in this geometry of the samples. For more precise determination of stress, when formation of localized shear band starts, for determination of shear strain and strain rate in the zone of local shear, it is required to perform a series of tests with use of loading pulses having various durations. In these tests, character of growth of shear localization in material will be recorded at various stages (from beginning of localized shear to total shear). Also it is required to perform a joint analysis of obtained mechanical characteristics and parameters of microstructure changed during shear.

The obtained results will be helpful for development of the model of formation and growth of adiabatic shear bands.

\section{References}

1. H.C. Rogers, Ann. Rev. Mater. Sci., 9, 283-311 (1979)

2. Y. Bai, B. Dodd, Adiabatic Shear Localization (Pergamon Press, Oxford, United Kingdom), 24-53 (1992)

3. Q. Xue, G.T. Gray III, B.L. Henrie, S.A. Maloy, S.R. Chen, Metall. Mater. Trans. A, 36A, 1471-1486 (2005)

4. Q. Xue, G.T. Gray III, Metall. Mater. Trans. A, 37A, 2435-2446 (2006)

5. P. Longere, A. Dragon, H. Trumel, X. Deprince, Int. J. Impact Engineering, 32, 285-320 (2005)

6. K.H. Hartman, H.D. Kunze, L.W. Meyer, Shock Waves and High-Strain-Rate Phenomena in Metals (Plenum Press, New York, USA), 325-337 (1981)

7. A.P. Bol'shakov, A.M. Bragov, N.N. Gerdyukov et al., Study of dynamic strength of structural materials. Textbook/SarPhTI (Publishing House "Krasnyi Oktyabr", Saransk, Russia), 38-45 (2003) 